\title{
Sources of weaning advice, comparisons between formal and informal advice, and associations with weaning timing in a survey of UK first-time mothers
}

\author{
Amanda P Moore ${ }^{1}$, Peter Milligan ${ }^{1}$, Carol Rivas ${ }^{2}$ and Louise M Goff ${ }^{1, *}$ \\ 'Diabetes \& Nutritional Sciences Division, Franklin-Wilkins Building, Room 4.10, School of Medicine, King's \\ College London, Stamford Street, London SE 1 9NH, UK: ${ }^{2}$ Centre for Health Sciences, Blizard Institute, Barts and \\ The London School of Medicine and Dentistry, London, UK
}

Submitted 18 May 2011: Final revision received 25 January 2012: Accepted 20 April 2012: First published online 28 May 2012

\begin{abstract}
Objective: The aim of the present study was to explore knowledge of the UK weaning guidelines and the sources of weaning advice used by UK first-time mothers.

Design: An online survey of UK parents; analysed using mixed methods.

Setting: Participants were recruited from a selection of parenting websites that hosted a link to the survey.

Subjects: In total, 1348 UK first-time mothers were included in the analysis.

Results: Knowledge of the guidelines was high (86\%) and associated with later weaning $(P<0 \cdot 001)$, although $43 \%$ of this sample weaned before 24 weeks. The majority of parents used multiple sources of information, the most influential being the health visitor (26\%), the Internet (25\%) and books (18\%). Fifty-six per cent said they received conflicting advice. Younger mothers and those of lower educational attainment were more likely to be influenced by advice from family, which was likely to be to wean earlier. Furthermore, those most influenced by their mother/grandmother were less likely to have accurate knowledge of the guidelines. In this population the Internet was used for weaning advice across all sociodemographic groups and was associated with a later weaning age, independently of sociodemographic factors $(P<0 \cdot 001)$. Data from responses to a free-text question are used in illustration.

Conclusions: The study suggests that first-time mothers have a good understanding of the weaning guidelines but seek weaning information from multiple sources, much of which is conflicting. Informal sources of weaning advice appear most influential in younger mothers and those of lower educational attainment, and result in earlier weaning.
\end{abstract}

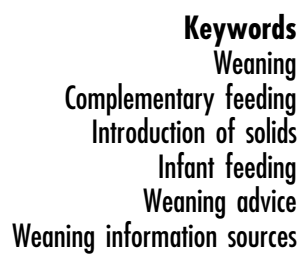

The timing of the introduction of solid food to an infant's diet is important for nutritional and developmental reasons $^{(1)}$. In 2003 the UK Department of Health (DH) adopted the WHO guidelines to introduce complementary foods at 6 months ${ }^{(2,3)}$; however, there has been considerable debate among health professionals about the appropriateness of these guidelines ${ }^{(4-6)}$ and the Scientific Advisory Committee on Nutrition is currently reviewing complementary and infant feeding recommendations for the $\mathrm{UK}^{(7)}$.

Evidence suggests that compliance with the UK weaning guidelines is low; the latest nationwide study (2005) concluded that $98 \%$ of parents introduced solids before 26 weeks $^{(8)}$. Previous studies have indicated that the parental decision to begin weaning earlier than recommended is associated with a range of signals, such as the infant waking at night, seeming hungry or unsatisfied by milk, or reaching for food ${ }^{(9-11)}$. However, despite clarification from the $\mathrm{DH}^{(12)}$, there is little consensus among mothers about the cues they deem significant ${ }^{(10)}$. Given that readiness for solids is a developmental process, there has been the suggestion that health visitors may also find it difficult to remain consistent with published guidelines while offering advice tailored to signals from the infant ${ }^{(9,10)}$ and as a result commonly suggest weaning earlier than the guidelines ${ }^{(13)}$.

There has been little UK research into sources of weaning advice. A small Irish survey ( $n$ 215) concluded that advice from health visitors was the most important source of feeding advice; however, it highlighted that grandparents and the Internet were also influential ${ }^{(14)}$. Reliance on informal advice, from family in particular, 
has been associated with earlier weaning ${ }^{(8,15,16)}$, while receiving advice from health professionals is associated with later weaning ${ }^{(8)}$. Qualitative research suggests that mothers in the UK can be confused by conflicting advice and that first-time mothers may find this creates anxiety around weaning ${ }^{(10)}$.

The present study explored which sources of information first-time parents used and found most influential when making the decision of when to wean and associations between sources of advice, knowledge of the guidelines and weaning timing. Our results may help health professionals understand how well weaning messages are being communicated among first-time mothers in the UK and how the influence of sources of weaning advice may shape weaning behaviour in the context of other influential factors.

\section{Methods}

An online survey of UK parents was performed (using the SurveyMonkey ${ }^{\circledR}$ online survey software and questionnaire tool) in accordance with the ethical standards of King's College London Research Ethics Committee (BDM09/ 10-61). Parents were recruited via a link on a selection of online parenting websites, over a 3-week period (June 2010). The questionnaire was completed anonymously.

\section{Participants}

Eligible participants were first-time parents who had weaned a child since the 2003 guidelines and were UK residents. Data were excluded from the analysis if the infant was weaned early or late for medical reasons. A series of explicit questions was used to assess all inclusion criteria.

\section{Survey}

The questionnaire consisted of twenty-one questions in themed sections: weaning timing; understanding of the guidelines; factors influencing weaning timing; sources of information; antenatal care and feeding choices during the first 6 months; and feelings about the weaning process. The questionnaire was piloted to verify understanding and resulted in minor changes to the wording of two questions.

\section{Analysis}

Quantitative analysis

Quantitative data were analysed using the SPSS statistical software package version $19 \cdot 0$. Non-parametric tests were used to assess the relationship between categorical variables. One-way ANOVA modelling was performed using the ranked weaning data due to the categorical and ordinal nature of the data. Partially completed questionnaires were included in selected analyses, as appropriate, therefore responses are reported as valid percentages. Analysis was carried out to confirm the effects of missing data on key findings. In all instances $P>0.05$ (data not shown), leading us to conclude that our conclusions are robust, despite missing data. Logistic regression analysis was used to investigate whether the most influential source of advice was a predictor of accurate knowledge of the weaning guidelines (knowledge of the current weaning guidelines was deemed as accurate if stated as at 6 months (26 weeks) or around 6 months, reflecting the definitions given in $\mathrm{DH}$ guidelines ${ }^{(2)}$ and the DH consumer leaflet ${ }^{(12)}$, respectively). The terms used in the model were 'most influential source of advice' as a block of categorical indicator variables (as listed in Table 2). Educational attainment, receipt of benefits, ethnicity and maternal age were entered into the model as confounding variables. The indicator variables were entered into the model as a block and the odds ratio statistics are reported in relation to the reference category (friends). The reference category was selected based the number of participants and the median weaning age being closest to the median weaning age of the sample as a whole. The Wald test provides a statistic for the overall significance of how reliable the indicator variables are in predicting the outcome. The odds ratios and confidence intervals indicate how each alternative within the indicator variables contributes towards the overall influence and how each may influence the likelihood.

\section{Qualitative analysis}

Free-text responses regarding weaning advice were analysed using the corpus analysis tool WMatrix ${ }^{(17)}$ to identify significant keywords, phrases and semantic groupings. Keyword analysis is recommended for use with large volumes of qualitative data ${ }^{(18)}$. This approach identifies words that occur more frequently in the text of interest than they do in the reference text as 'keywords'. Compared with other qualitative methodologies, keyword analysis is a more inductive approach as meaning is inferred only after identification of the keywords ${ }^{(18)}$. The log-likelihood (LL) statistic from the keyword analysis is quoted as an indication of significant themes $(P \leq 0 \cdot 05, \mathrm{LL}>3 \cdot 84)$ for further investigation in subsequent thematic content analysis. For this we used NVivo $9 \cdot 0$ software for data management and followed Muller's five-step approach ${ }^{(19)}$. One person led on the analysis, with thematic codes verified by the other authors. Given that the data were often one-sentence answers to an open question, there were no major issues from potential biases or from ambiguity in coding, and a code book was not necessary. As the data were written responses, affect was often signified by punctuation, further informing interpretation.

\section{Results}

A total of 1348 first-time parents were included in the study (Table 1), of whom $99 \cdot 7 \%$ were the baby's mother, 
Table 1 Characteristics of respondents and comparative weaning ages: sample of 1348 first-time mothers recruited via online parenting websites, UK, June 2010

\begin{tabular}{|c|c|c|c|c|c|c|}
\hline \multirow[b]{2}{*}{ Characteristic } & \multirow[b]{2}{*}{$n$} & \multirow[b]{2}{*}{$\% *$} & \multicolumn{3}{|c|}{ Age at weaning (weeks) } & \multirow[b]{2}{*}{$P$ (Kruskal-Wallis) } \\
\hline & & & Mean & SD & Median & \\
\hline \multicolumn{7}{|l|}{ Maternal age (mean $32 \cdot 0$, sD 4.9 years) } \\
\hline$\leq 25$ & 119 & 9 & 20 & 4.5 & $20+$ & $<0.001$ \\
\hline $26-33$ & 731 & 55 & 23 & $3 \cdot 4$ & $24 t$ & \\
\hline$\leq 34$ & 473 & 36 & 23 & $3 \cdot 4$ & $24 t$ & \\
\hline \multicolumn{7}{|l|}{ In receipt of benefits } \\
\hline No & 1141 & 91 & 23 & 3.5 & 24 & $<0.001$ \\
\hline Yes & 106 & 9 & 21 & $4 \cdot 4$ & 22 & \\
\hline \multicolumn{7}{|l|}{ Marital status } \\
\hline Single or divorced & 79 & 6 & 21 & $4 \cdot 8$ & $21 \ddagger$ & $<0.001$ \\
\hline Co-habiting & 256 & 20 & 22 & $4 \cdot 0$ & $23 \ddagger$ & \\
\hline Married & 975 & 74 & 23 & $3 \cdot 3$ & $24 \ddagger$ & \\
\hline \multicolumn{7}{|l|}{ Educational attainment } \\
\hline To 16 years & 229 & 18 & 21 & $4 \cdot 3$ & $22 \S$ & $<0.001$ \\
\hline To 18 years (HND/HNC or equivalent) & 161 & 12 & 22 & 3.5 & $23 \S$ & \\
\hline Degree or equivalent & 911 & 70 & 23 & $3 \cdot 2$ & $24 \S$ & \\
\hline \multicolumn{7}{|l|}{ Ethnicity } \\
\hline Caucasian & 1233 & 95 & 23 & $3 \cdot 6$ & 24 & 0.858 \\
\hline Other & 63 & 5 & 23 & $3 \cdot 2$ & 24 & \\
\hline \multicolumn{7}{|l|}{ Feeding method $0-8$ weeks } \\
\hline Exclusive breast-feeding & 898 & 68 & 23 & $3 \cdot 2$ & $24 \|$ & $<0.001$ \\
\hline Formula milk only & 195 & 15 & 20 & $4 \cdot 2$ & $20 \|$ & \\
\hline Mixed feeding (breast/formula) & 229 & 17 & 22 & $3 \cdot 6$ & $23 \|$ & \\
\hline
\end{tabular}

HND, Higher National Diploma; HNC, Higher National Certificate.

*Valid percentages.

+Significant differences between $\leq 25$ years and 26-33 years $(P<0.001)$ and $\leq 25$ years and $\leq 34$ years $(P<0.001)$.

$\ddagger$ Significant differences between single and co-habiting $(P=0.010)$, single and married $(P<0.001)$ and cohabiting and married $(P=0.034)$.

$\S$ Significant differences between educated to degree and to 16 years $(P<0.001)$ and to 18 years $(P<0.001)$.

II Significant differences between all groups $(P<0 \cdot 001)$.

$70 \%$ were educated to degree level and $68 \%$ exclusively breast-fed for the first 8 weeks. Thirty-four per cent of participants had a child below the age of 1 year and $60 \%$ had a child aged $1-3$ years.

\section{Knowledge of the guidelines}

Knowledge of the current guidelines was high (86\%), although they were less well understood among mothers under 25 years old $(P<0 \cdot 001)$, in receipt of benefits $(P=0 \cdot 001)$ and educated until 16 years old $(P=0 \cdot 001)$. Knowledge of the guidelines had a positive association with weaning age $\left(\chi^{2}(3, n 1345)=105 \cdot 8, P<0 \cdot 001\right.$; Fig. 1$)$, which remained significant in ANOVA after adjustment for demographic factors $(F(1,1199)=60 \cdot 0, P<0 \cdot 001)$. However, knowledge of the guidelines did not necessarily result in compliance, as $43 \%$ still weaned before 24 weeks. The most influential source of advice was an independent predictor of having accurate knowledge of the weaning guidelines (Wald $=42 \cdot 3, \quad P<0 \cdot 001$ ), with books and the Internet increasing the likelihood to a significant degree and being influenced by the mother/grandmother decreasing it (Table 2).

\section{Sources of weaning information}

First-time mothers relied on multiple sources of feeding advice, $74 \%$ using more than three sources. Fifty-six per cent reported receiving conflicting advice, most apparent in younger mothers $\left(\chi^{2}(8, n 1302)=43 \cdot 1, P<0 \cdot 001\right)$.

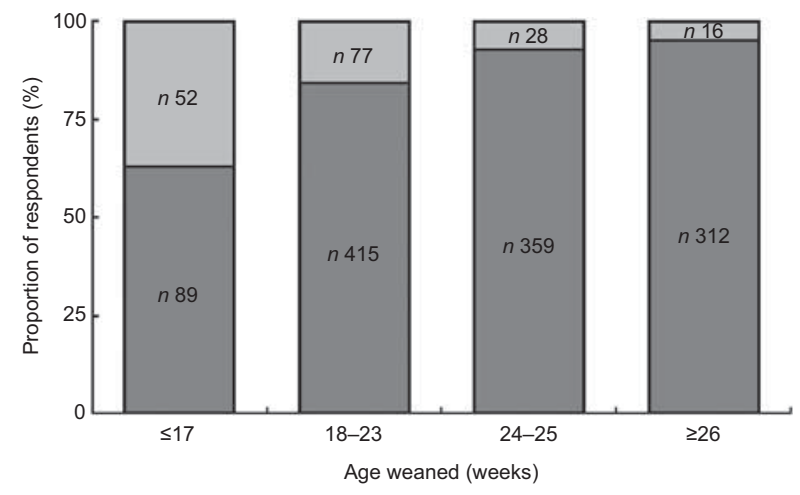

Fig. 1 Understanding ( $\square$, accurate; $\square$, inaccurate) of the UK weaning guidelines and weaning timing $\left(\chi^{2}(3, n 1348)=105 \cdot 8\right.$, $P<0.001)$ in a sample of 1348 first-time mothers recruited via online parenting websites, UK, June 2010

\section{Formal advice}

Seventy-seven per cent of respondents received weaning advice from a health visitor but only $26 \%$ deemed this the most influential source of advice (Table 3 ). Other sources of formal advice included leaflets (56\%), the general practitioner (17\%) and other health professionals (dietitians, pharmacists or other medical professionals; $14 \%$ ). Mothers were equally likely to receive advice from a health visitor regardless of their age $\left(\chi^{2}(3, n 1348)=4 \cdot 56, P=0 \cdot 207\right)$, being in receipt of benefits $\left(\chi^{2}(1, n 1348)=0.54, P=0.570\right)$ or ethnicity $\left(\chi^{2}(2, n 1348)=0 \cdot 56, P=0 \cdot 760\right)$. The mean age 
Table 2 Logistic regression analysis for influence of most influential source of information as a predictor of accuracy of knowledge of the UK weaning guidelines ( $n 1114$; Cox \& Snell $\left.R^{2}=0.062\right)$ in a sample of first-time mothers recruited via online parenting websites, UK, June 2010

\begin{tabular}{|c|c|c|c|c|c|c|c|}
\hline & $n^{\star}$ & $\%$ & Wald & df & $P$ & OR & $95 \% \mathrm{Cl}$ \\
\hline Most influential source of information & & & $42 \cdot 3$ & 6 & $<0.001$ & & \\
\hline Health visitor & 310 & 26 & $2 \cdot 15$ & & 0.142 & $1 \cdot 49$ & $0 \cdot 88,2 \cdot 54$ \\
\hline GP or other & 16 & 1 & 1.51 & 1 & 0.220 & 0.46 & $0.14,1.58$ \\
\hline Leaflets & 53 & 5 & 1.94 & 1 & $0 \cdot 163$ & $2 \cdot 18$ & $0.73,6.55$ \\
\hline Books & 212 & 18 & $3 \cdot 89$ & 1 & 0.049 & $1 \cdot 89$ & $1 \cdot 00,3 \cdot 57$ \\
\hline Internet & 278 & 25 & $7 \cdot 93$ & 1 & 0.005 & $2 \cdot 43$ & $1 \cdot 31,4 \cdot 52$ \\
\hline Mother/grandmother & 115 & 10 & 8.99 & 1 & 0.003 & 0.42 & $0.24,0.74$ \\
\hline Friendst & 201 & 16 & & & & $1 \cdot 00$ & \\
\hline
\end{tabular}

GP, general practitioner.

Confounding variables: educational attainment (categorical; Wald $=21 \cdot 8, P<0 \cdot 001$ ), ethnicity (dichotomous), receipt of benefits (dichotomous) and maternal age (numeric).

*Number used in the regression analysis.

tDenotes reference category.

Table 3 Most influential source of advice and weaning age (weeks) in a sample of first-time mothers recruited via online parenting websites, UK, June 2010

\begin{tabular}{|c|c|c|c|c|}
\hline & \multirow{2}{*}{$\frac{\text { Advice received from... }}{\%}$} & \multicolumn{3}{|c|}{ Most influential advice } \\
\hline & & $n$ & $\%$ & Weeks weaned (median) \\
\hline Health visitor & 77 & 310 & 26 & 24 \\
\hline Internet & 88 & 278 & 25 & 25 \\
\hline Books & 81 & 212 & 18 & 24 \\
\hline Mother/grandmother & 68 & 115 & 10 & 20 \\
\hline Friends with same aged children & 78 & 111 & 9 & 22 \\
\hline Friends with older children & 70 & 90 & 7 & 22 \\
\hline Leaflet & 56 & 53 & 5 & 24 \\
\hline GP or other medical professional & 31 & 16 & 1 & 21 \\
\hline Total & & 1185 & 100 & 23 \\
\hline
\end{tabular}

GP, general practitioner.

of the child when mothers received feeding advice from a health visitor was 16 (SD 4.75) weeks. Forty-two per cent of respondents indicated that their health visitors recommended they wean at around 6 months, $34 \%$ at 6 months and $24 \%$ advised to wean earlier or to be governed by signs from the baby (Fig. 2).

Thematic content analysis of the free-text responses ( $n$ 162) about weaning advice from health visitors revealed a number of key themes (Table 4); most dominant was that the health visitor advised beginning weaning based on an observed need or sign from the infant or a practical need of the mother (returning to work). The keyword analysis (Table 5) supports this tailoring of advice, with the words 'due to' having a higher relative frequency when compared with advice given from friends and family (LL $=7 \cdot 9, \quad P<0 \cdot 001$ ) and normal speech $(\mathrm{LL}=80 \cdot 4, P<0 \cdot 0001)$. The most common reasons cited by the health visitor as a need to begin weaning were to improve weight gain or to help reflux, followed by helping the baby to sleep:

I was told generally about waiting until 6 months but that they do advise on a case-by-case basis and as my baby was not gaining weight I was advised to start. (18)
Generally this was interpreted positively and semantic groupings for supportive words such as 'guidance', 'said it was OK' and 'supportive' were significant in evaluation by WMatrix compared with normal speech $(\mathrm{LL}=24 \cdot 6$, $P<0 \cdot 0001)$ and advice from friends and family (LL $=7 \cdot 9$, $P<0 \cdot 001)$ :

She gave me advice and recipes ... which was invaluable. (6)

Advised to wean slightly early on medical grounds, but I was given full info and the choice was very much my own. (40)

However, being given conflicting advice from health visitors was also common:

My health visitor told me to start weaning as my baby wasn't gaining enough weight ... the next health visitor told me off for starting way too early. (60)

One said [I] should wait until 6 months, one said I was unlikely to make it anywhere near that point with such a big baby so I should start from 17 weeks. (138)

Groups of words suggesting conflict, such as 'different', 'confused', 'mixed' and 'conflicting', were common in the 
health visitor data compared with normal speech ( $\mathrm{LL}=$ $28 \cdot 8, P<0 \cdot 001)$ although these words were also common in advice given by friends and family.

A feeling that the health visitor gave poor advice, was not well informed, or was less able than the mother to interpret the infant's needs, was apparent for some mothers when the health visitor was suggesting weaning

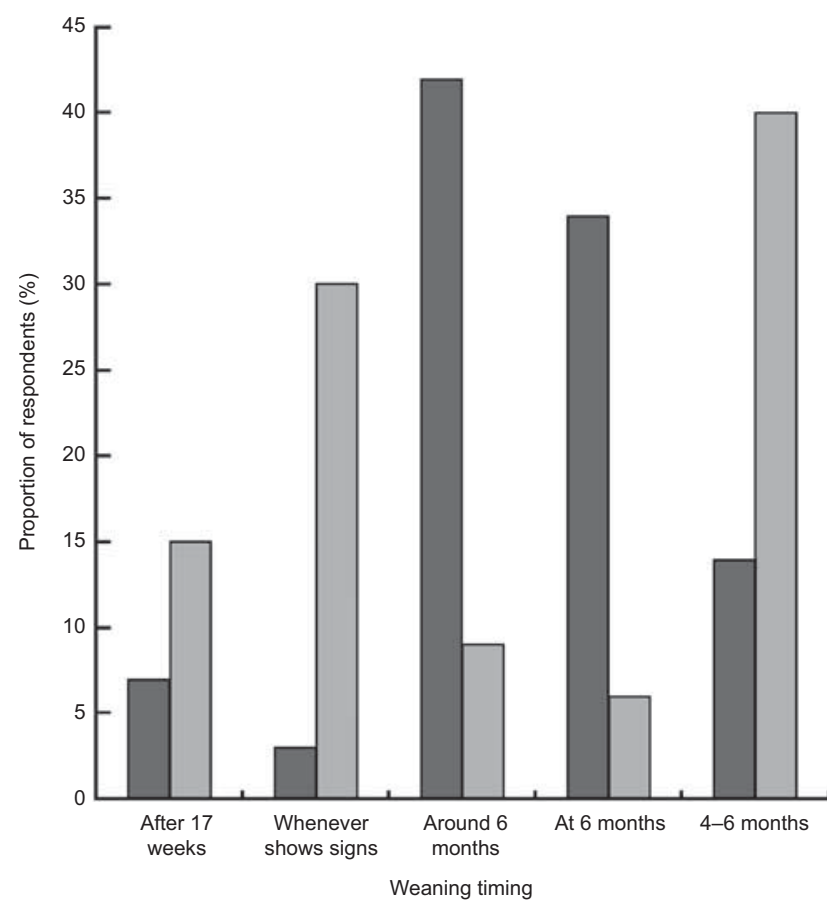

Fig. 2 Proportions receiving advice on weaning timing from formal ( $\square$, health visitor, $n 812$ ) and informal sources ( $\square$, friends and family, $n$ 1007) in a sample of 1348 first-time mothers recruited via online parenting websites, UK, June 2010 before 6 months; but also conversely when waiting until 6 months was suggested rather than responding to the needs of the infant:

She wanted me to start at 4 months and kept telling me I was missing 'the window of opportunity'. I eventually lied and told her we'd started when we hadn't. (64)

I was told I HAVE to start weaning at 18 weeks. I refused as there is a natural plateau in weight gain around 16-18 weeks. (90)

Around 4 months ... I ignored it since I was much better educated about breast feeding than the health visitor. (677)

Commonly used words such as 'ignored' and [I] 'refused' (LL $=13 \cdot 9, P<0 \cdot 0001$ and $\mathrm{LL}=12 \cdot 9, P<0 \cdot 001$, checked in context) suggest that some mothers felt they knew better.

There appeared to be variability in the health visitor interpretation of the guidelines from rigidity to an idea that they were not attainable for most parents, and in some cases no reference to the guidelines was made:

I was told I MUST NOT wean before 6 months, which I found very unhelpful. (579)

I was advised that 6 months was the gold standard but that not many mothers get that far. (776)

I was advised 4 months was when to start weaning. (595)

\section{Informal advice}

A variety of informal sources of weaning advice were used, such as the Internet (used by $88 \%$ ), books ( $81 \%$ ),

Table 4 Dominant themes from comparative content analysis of advice from health visitors and advice from family and friends in a sample of first-time mothers recruited via online parenting websites, UK, June 2010

\begin{tabular}{lcc}
\hline & $n^{\star}$ & $\%$ coveraget \\
\hline Health visitor & 40 & 26 \\
Health visitor advised me to wean (earlier) due to... & 17 & 18 \\
Advice from my health visitors conflicted & 15 & 15 \\
Health visitor advice was poor & 14 & 10 \\
Health visitor advice was supportive/flexible & 10 & 12 \\
Health visitor advised the guidelines were 6 months but earlier was normal & 7 & 3 \\
Health visitor advised via leaflet or classes & 4 & 2 \\
My baby had specific needs or was referred to a medical practitioner & 4 & 2 \\
I was advised I must not consider weaning before 6 months & 84 & 33 \\
Family and friends & 65 & 31 \\
Before 17 weeks & 26 & 11 \\
Advice was conflicting & 24 & 11 \\
I ignored the advice or considered it irrelevant & 23 & 8 \\
Wean to help baby sleep through the night & 14 & 8 \\
Wean around 6 months & 16 & 7 \\
Cited experience of previously weaning early, without negative consequences & 11 &
\end{tabular}

${ }^{*}$ Ten responses were not coded as content did not describe advice given.

tSome responses were coded multiple times according to content. 
Table 5 Keywords and themes identified in analysis of free-text responses in a sample of first-time mothers recruited via online parenting websites, UK, June 2010

\begin{tabular}{|c|c|c|}
\hline Semantic grouping* & Health visitor ${ }^{*}+\ddagger$ & Friends and family ${ }^{\star} \ddagger \S$ \\
\hline Advice/speech acts & told, asked, advised, suggested, discussed & $\begin{array}{l}\text { advised, suggested, recommended, nags/nagged, } \\
\text { swears (by), pressurised }\end{array}$ \\
\hline Food & hungry & hungry, rice, rusk, soup, cereal, biscuits \\
\hline Numbers & 6 (months), 17 (weeks) & 3 (months), 12 (weeks), 8 (weeks) \\
\hline Difference & $\begin{array}{l}\text { different, confused, mixed, conflicting, } \\
\text { disagreed }\end{array}$ & $\begin{array}{l}\text { different/differed/differing, conflicting, various/varied, } \\
\text { mixed, range, combination (of multiple-choice options) }\end{array}$ \\
\hline Supportive/positive evaluation & $\begin{array}{l}\text { ok, fine, help (with sleeping, reflux, weight), } \\
\text { supportive, guided }\end{array}$ & help (sleep)\| \\
\hline Inattentive & ignored, refused & ignore(d), refused, disagreed \\
\hline Appearance & seemed ready, ready, signs & \\
\hline Cause and effect & due to, showed signs & based on, depending on, due to \\
\hline Objects & leaflet, booklet & bottle (add solids to) \\
\hline Physiology & reflux, weight (slowed, gain) & sleep, waking/woke, sleep through \\
\hline Negative evaluation & & unhelpful, ridiculous \\
\hline
\end{tabular}

${ }^{*} \mathrm{LL}$ (log-likelihood) $=6.63$ or higher for semantic group or word frequency $(P<0.001)$ compared between groups and/or with normal speech.

tWords listed in each section in order of relative frequency comparing health visitor advice with normal speech.

$\ddagger$ Collocation of surrounding words given in brackets to clarify most common use in context. Words in bold indicate high relative frequency in this group compared with the other $(P<0.001)$.

$\S$ Words listed in each section in order of relative frequency comparing friends and family with normal speech.

\|Under-use of positive evaluation compared with health visitor advice $(P<0.001)$.

friends (78\%) and the baby's grandmother (68\%). The Internet and books were most influential for $25 \%$ and $18 \%$ of respondents, respectively (Table 3). The most common advice from family and friends was to wean between 4 and 6 months (40\%) or when the infant showed signs of being ready (30\%), while $15 \%$ advised weaning at or around 6 months and $15 \%$ waiting until after 17 weeks (Fig. 2).

Thematic content analysis of the free-text responses ( $n$ 268) about weaning advice from friends and family revealed a number of dominant themes (Table 4). The family commonly suggested weaning early (before 17 weeks and usually at 8 or 12 weeks), often based upon experience of the previous generation being weaned much earlier without negative consequences:

... his father was weaned at 8 weeks it didn't do him any harm!!! (600)

The numbers 3 (months)/12 (weeks) and 8 weeks were more likely to be cited by informal sources than when health visitor advice was described ( $L L=31 \cdot 3$, 20.0 and $11 \cdot 6$, respectively, $P<0 \cdot 001$ ), in which case 6 (months) and 17 (weeks) were more commonly observed. Beginning weaning was suggested when the baby seemed unsatisfied by milk or to help night-time waking, and putting solids into a bottle as early as a week after birth was often suggested. The range of conflicting advice given was apparent in the responses and much of the advice was considered unsolicited or irrelevant:

Friends, family and passing strangers gave all sorts of nonsensical conflicting advice. (665)

Mum and mum-in-law started the weaning nag at 12 weeks! (803)
Everyone had an opinion although none was asked for. (679)

I had every advice going. (777)

The word 'conflicting' appeared frequently (LL $=121 \cdot 4$, $P<0 \cdot 001)$.

Compared with health visitor advice, advice from friends and family was described using fewer obligation words such as 'told' (LL $=17 \cdot 1, P<0 \cdot 0001$ ), 'must', 'had to' and 'should'. On the other hand, informal words such as 'nag(ged)' or 'pressurised' still suggested an obligation was imposed on the mothers to follow advice; however, mothers were prepared to confidently reject advice they didn't agree with. As with the advice from health visitors, 'ignore(d)' occurred frequently in the discussion of advice from friends and family ( $\mathrm{LL}=63 \cdot 5, P<0 \cdot 0001)$ :

I decided to listen to the people who's parenting I thought was closest to mine. (641)

I was given conflicting advice but the advice I most trusted was to wean at 6 months. (759)

My mum said she had me on baby rice at 3 weeks!! Which I chose to ignore. (812)

...advised weaning at 3 months, which I ignored. (618)

\section{Associations between the most influential sources of advice and weaning timing}

The most influential source of advice varied according to maternal age $\left(\chi^{2}(12, n 1160)=42 \cdot 2, P<0 \cdot 001\right)$ and maternal education $\left(\chi^{2}(12, n 1164)=58 \cdot 7, P<0 \cdot 001\right)$. Relying on advice from a mother or grandmother was more likely in mothers under 25 years and those educated to 16 or 18 years, while formal advice from health professionals was 
more influential in mothers over 34 years. Those with tertiary education were more likely to be influenced by books. The Internet was used as an information source equally across all age and educational groups, although it was less often cited as the most influential source in those who finished formal education at 16 years.

There was an association between the type of advice that was most influential and weaning age $\left(\chi^{2}(6\right.$, $n$ 1185 $)=121 \cdot 8, P<0 \cdot 001$; independent of demographic factors $(F(6,1089)=22 \cdot 8, P<0 \cdot 001))$, with $55 \%$ of those weaning before 17 weeks being most influenced by friends and family and $59 \%$ of those weaning at 6 months being most influenced by books and the Internet. Reliance on a grandparent for weaning advice was associated with the earliest weaning age (Table 3 ).

\section{Other influences on weaning timing}

The triggers to wean before 6 months were more likely to be in response to a signal from the infant $(64 \%$ cited developmental signs as having a lot of influence) than due to prompts from external advice (26\%). Forty-one per cent said they began weaning when their baby was 'the right age'. Ten per cent said the baby waking at night had a lot of influence and this was associated with weaning before 20 weeks $\left(\chi^{2}(9, n 1250)=170 \cdot 2\right.$, $P<0 \cdot 001)$, while those weaning after 24 weeks were more influenced by the baby's age $\left(\chi^{2}(9, n 1297)=202 \cdot 8\right.$, $P<0 \cdot 001)$. Seventy-one per cent were confident about when to wean, $36 \%$ reported anxiety and $25 \%$ were confused. Confusion was higher among younger mothers $\left(\chi^{2}(4, n 1296)=11 \cdot 2, P=0 \cdot 025\right)$.

\section{Discussion}

Using quantitative and qualitative methodology, the present study explores the primary sources of weaning advice for first-time mothers and compares the advice given informally with that reported to have been given by health visitors. Associations with weaning knowledge and weaning timing are investigated. Previously, sources of weaning advice have primarily been reported in smaller studies ${ }^{(11,14)}$.

First-time motherhood can be an unsettling period when lack of knowledge can lead mothers into information-seeking behaviour ${ }^{(20)}$. The search for weaning information appears to be no exception, with the majority in the current study seeking information from multiple sources. While information from health visitors was often cited as the most influential source of weaning information, the fact that only a quarter of these mothers were most influenced by this advice and that the importance of the Internet and books was highlighted suggest, certainly in this educated population, that self-driven research was also important. While information from books was more influential for those with tertiary education, the study shows that the Internet was used by a broad social crosssection of mothers as has previously been acknowledged by the founder of Netmums ${ }^{(21)}$. As the present study used an Internet-sourced sample, recruitment bias should be considered. However, in their telephone-based study, Gildea et al. (2009) also reported the usefulness of the Internet for weaning information across $75 \%$ of respondents ${ }^{(14)}$. Moreover, the fact that the Internet, while used by $88 \%$, was the primary influence in only $25 \%$ of cases also indicates the general validity of our findings. Clearly, the increasing importance of the Internet and Internet forums should be recognised in devising weaning communication strategies. Over half of this population used printed leaflets; they were rarely cited as a key influence but appeared commonly in free-text descriptions of health visitor advice. There have been few evidence-based studies reviewing weaning interventions; however none using printed information alone were effective and evidence suggests that printed advice should be accompanied by regular support from a health professional $^{(22)}$. Advice from friends and family was commonly given, although was mainly influential for younger mothers and those of lower educational attainment, as also found in the study by Gildea et $a l .{ }^{(14)}$. The need for increased family support is understandable given the social pressures associated with motherhood at a young age $\mathrm{e}^{(23,24)}$. However, as reliance on advice from family, particularly the previous generation, has generally been shown to perpetuate inappropriate early weaning $^{(8,15,16)}$, the need for weaning support in this vulnerable group is highlighted. For the younger, less well-educated mothers it remains a concern that health professionals may not be saliently communicating the negative health consequences of weaning before 17 weeks, as well as information about the weaning guidelines. It is also necessary for professional communication to reach the influential previous generation; this is a challenging proposition, especially since they have weaned earlier in the past with no apparent negative consequences. Weaning advice also needs to be timely; for mothers most influenced by the previous generation, receiving advice at 16 weeks may be too late.

The present study indicates a degree of variability in how health visitors interpret the guidelines. Health visitors are the most likely health professionals to give infant feeding advice to postnatal mothers in the UK, although dietitians and physicians may advise in particular situations if there is medical need. Women in the study indicated they saw multiple health visitors who often advised differently, leading to conflict and a lack of confidence in the advice they received. Most health visitors were reported to suggest weaning in response to the needs of the infant, indicating a primary focus to tailor advice to the individual. This is not surprising and is the way the guidelines were intended to be interpreted ${ }^{(25)}$. However, there was evidence from the present data that 
for some mothers focused on achieving the 6 months guidelines, advice to wean earlier, according to the health visitor's perception of the infants' needs, was frustrating or a sign that they were not knowledgeable. This was particularly the case when the signs they suggested, such as failure to maintain weight gain or waking at night, were not consistent with those promoted by the $\mathrm{DH}^{(12)}$. The current study confirms findings from a recent qualitative study ${ }^{(10)}$, that those waiting until 6 months to wean are generally focused on the baby's age and achieving the guidelines and less so on putative signs of readiness in the infant. This highlights the difficult situation faced by health visitors; with some mothers they risk their credibility if they don't acknowledge the guidelines, while for others focusing on the guidelines can create stress if mothers don't feel they can wait until 6 months. With the online resources available today's mothers can be well informed, as was evident in this well-educated group. Evaluation of successful health visitor-client interactions, particularly with well-informed parents, indicates that an approach that 'facilitates individuals to make choices which are right for them, providing information about health, which will help them in their decision making', rather than an authoritative approach in which health visitors position themselves as the expert, is more likely to be successful ${ }^{(26)}$. Both examples of interaction were found in the current study and it is likely that weaning information will be best received when the mother's position on the guidelines and existing weaning knowledge are acknowledged when discussing weaning. The recent British Dietetic Association position statement suggests that 'each infant should be managed individually and developmental signs of readiness ... and parental opinions should be taken into consideration' when advising on weaning and that weaning should begin between 17 weeks and 6 months ${ }^{(1)}$. The present study supports the British Dietetic Association's recommendations in that if health visitors promoted weaning around 6 months (rather than not before 6 months) it would lead to a greater consistency of advice within the framework of the existing guidelines, while allowing the health visitor to acknowledge the instinct of the mother in determining weaning timing and recognising that some infants need solids before 6 months ${ }^{(6)}$. This may be preferable to returning to the previous guidelines in which recommendations to wean between 4 and 6 months were often interpreted as to begin weaning at 16 weeks $^{(8)}$ and is consistent with the current evidence base as indicated in the most recent European Commission review ${ }^{(27)}$.

There has been little formal evaluation of interventions to promote optimal weaning behaviours. Of those that have been reviewed, the most successful involved regular, long-term support and 'how to' advice ${ }^{(22)}$. A recent investigation of the psychosocial factors important in the decision to delay weaning until 6 months reinforces the importance of social norms in determining this behaviour.
Mothers who perceived peer pressure ('the other mothers I know are doing this') or that it is a social norm to delay weaning were more likely to have the intention to do so. This was more important than perceiving a benefit in delaying weaning and highlights the importance of the maternal support network in establishing later weaning as a normal behaviour ${ }^{(28)}$.

\section{Limitations of the study}

The major strengths of the current study are its size, diversity and that it has captured 'the mother's voice'. However, the sample is primarily Caucasian, well-educated and the exclusive breast-feeding rate is high compared with the national average, so extrapolations to the general population are therefore difficult. It should also be recognised that this is a self-selected sample, reporting weaning behaviour retrospectively, and as such results are subject to associated biases. In addition, as responses were collected online, the multiple-choice answers may be open to misinterpretation that we are not aware of. Care should be taken when drawing conclusions about Internet usage due to recruiting bias. Advice given by the health visitor is as reported by parents. To evaluate health visitors' views about the guidelines, it is suggested that further analysis be carried out among a cross-section of health visitors.

\section{Conclusions}

The present study suggests that first-time mothers seek weaning information from multiple sources, much of which is conflicting. The younger, less well-educated mothers are highlighted as a group in particular need of support, because inappropriate early weaning is currently being perpetuated among them as their strongest influence is from the previous generation, who generally is not aware or supportive of weaning around 6 months. The Internet is likely to become an increasingly important communication vehicle for weaning information and health professionals should be able to direct mothers to reliable weaning information online.

It is recommended that further work be focused towards more vulnerable groups and with health visitors to investigate the difficulties they face in communicating weaning recommendations and to determine an interpretation of the guidelines that can be consistently delivered. Further evaluation of weaning interventions is necessary and those which involve education of significant others, such as the baby's grandmother, should be considered.

\section{Acknowledgements}

A.P.M. received a student bursary from the Organix Foundation to aid the publication of the present work; there are no other sources of funding. There are no conflicts of interest to declare. All listed authors made 
substantial contributions to the conception and design of the study, acquisition of the data, analysis and interpretation of data, drafting and revision of the article and final approval of the manuscript.

\section{References}

1. More J, Jenkins C, King C et al. (2010) Weaning Infants onto Solid Foods - BDA Paediatric Group Position Statement. Birmingham: British Dietetic Association.

2. Department of Health (2003) Infant Feeding Recommendation. http://www.dh.gov.uk/en/Publicationsandstatistics/ Publications/PublicationsPolicyAndGuidance/DH_4097197 (accessed June 2010).

3. World Health Organization (2003) Global Strategy on Infant and Young Child Feeding. http://www.who.int/nutrition/ publications/gs_infant_feeding_text_eng.pdf (accessed July 2010).

4. Agostoni C, Decsi T, Fewtrell M et al. (2008) Complementary feeding: a commentary by the ESPGHAN Committee on Nutrition. J Pediatr Gastroenterol Nutr 46, 99-110.

5. European Food Safety Agency, Panel on Dietetic Products, Nutrition and Allergies (2009) Scientific Opinion on the appropriate age for introduction of complementary feeding of infants. EFSA J 7, 1423-1461.

6. Fewtrell M, Wilson DC, Booth I et al. (2011) Six months of exclusive breast feeding: how good is the evidence? BMJ 341, 209-212.

7. Scientific Advisory Committee on Nutrition (2010) Draft Scope for Review of Complementary and Young Child Feeding. London: Scientific Advisory Committee on Nutrition.

8. Bolling K, Grant C, Hamlyn B et al. (2007). UK Infant Feeding Survey 2005. http://www.ic.nhs.uk/webfiles/ publications/ifs $06 / 2005 \% 20$ Infant $\% 20$ Feeding $\% 20$ Survey $\% 20 \%$ 28final\%20version\%29.pdf (accessed July 2010).

9. Anderson AS, Guthrie CA, Alder EM et al. (2001) Rattling the plate - reasons and rationales for early weaning. Health Educ Res 16, 471-479.

10. Arden MA (2010) Conflicting influences on UK mothers' decisions to introduce solid foods to their infants. Matern Child Nutr 6, 159-173.

11. White JM (2009) Weaning: what influences the timing? Community Pract 82, 34-37.

12. Department of Health \& UNICEF (2008) Weaning Starting Solid Food. London: Department of Health.
13. Department of Health (2010) Breastfeeding and Introducing Solid Food: Consumer Insight Summary. London: Department of Health.

14. Gildea A, Sloan S \& Stewart M (2009) Sources of feeding advice in the first year of life: who do parents value? Community Pract 82, 27-31.

15. Tarrant RC, Younger KM, Sheridan-Pereira M et al. (2010) Factors associated with weaning practices in term infants: a prospective observational study in Ireland. Br J Nutr 104, 1544-1554.

16. Alder EM, Williams FLR, Anderson AS et al. (2004) What influences the timing of the introduction of solid food to infants? Br J Nutr 92, 527-531.

17. Rayson P (2008) From key words to key semantic domains. Int J Corpus Linguistics 13, 519-549.

18. Seale C, Ziebland S \& Charteris-Black J (2006) Gender, cancer experience and internet use: a comparative keyword analysis of interviews and online cancer support groups. Soc Sci Med 62, 2577-2590.

19. Muller J (1999) Narrative approaches to qualitative research in primary care. In Doing Qualitative Research, pp. 221-238 [B Crabtree and L Miller, editors]. London: Sage.

20. George L (2005) Lack of preparedness: experience of first-time mothers. Am J Matern Child Nurs 30, 251-255.

21. Russell S (2006) Netmums: online support for parents. Community Pract 79, 44-45.

22. Higginson C (2001) Evidence into Action: Nutrition in the under-fives. Edinburgh: Health Education Board for Scotland.

23. John S (2011) Perceived environmental riak as a predictor of teenage motherhood. Health Place 17, 122-131.

24. Brewster K \& Billy J (1993) Social context and adolescent behaviour. The impact of community on the transition to sexual activity. Soc Forces 71, 713-740.

25. Scientific Advisory Committee on Nutrition (2001) SACN Committee Meeting, September 2001. http://www.sacn.gov. uk/meetings/committee/main_sacn_meetings/12062001.html (accessed June 2010)

26. Kendall S (1992) Do health visitors promote client participation? An analysis of the health visitor-client interaction. J Clin Nurs 2, 103-109.

27. European Union (2005) Directive 91/32/EER on Infant Formulae and Follow-on Formulae. Brussels: European Union.

28. Hamilton K, Daniels L, White K et al. (2011) Predicting mothers' decisions to introduce complementary feeding at 6 months. An investigation using an extended theory of planned behaviour. Appetite 56, 674-681. 